\title{
EDIFÍCIO E CIDADE: A REABILITAÇÃO DE VAZIOS COMO ESTRATÉGIA DE ENSINO DE PROJETO
}

\author{
MENEZES, Catarina Agudo \\ Centro Universitário Tiradentes- UNIT, e-mail: catarina.agudo@souunit.com.br \\ NOGUEIRA, Fabio Henrique Sales \\ Centro Universitário Tiradentes - UNIT, e-mail: fabio.sales@souunit.com.br \\ CAVALCANTI, Aline dos Santos Malta \\ Centro Universitário Tiradentes- UNIT, e-mail: aline.malta@souunit.com.br \\ MACIEL, Aline Santos \\ Centro Universitário Tiradentes - UNIT, e-mail: aline.maciel@souunit.com.br
}

\begin{abstract}
RESUMO
Este artigo apresenta o processo de ensino e resultados, da disciplina de Projeto de Arquitetura, Urbanismo e Paisagismo Vl, do curso de Arquitetura e Urbanismo, do Centro Universitário Tiradentes (Unit), em Maceió-AL. A disciplina abordou utilização de vazios urbanos em áreas centrais para fins de habitação de interesse social e a reabilitação de edifícios abandonados. $O$ principal objetivo foi promover a discussão quanto à problemática da moradia no Brasil apostando no projeto para minimizar tais problemas. A metodologia utilizada priorizou a concepção projetual integrada por meio da elaboração de diagnóstico urbanístico e desenvolvimento projetual em diferentes níveis. Assim pretende-se contribuir com as discussões quanto à formação do estudante de arquitetura e urbanismo, ciente dos problemas da sociedade e de seu papel social, enquanto agente transformador do espaço urbano.
\end{abstract}

Palavras-chave: Habitação de interesse social, Vazios edificados, Projeto de arquitetura

\begin{abstract}
This article presents the process of teaching and results of the subject of Architecture Design, Urbanism and Landscaping $\mathrm{Vl}$, from the Architecture and Urbanism course, at the Tiradentes University Center (Unit), in Maceió-AL. The subject addressed the use of urban gaps in central areas for social housing purposes and the rehabilitation of abandoned buildings. The main purpose was to promote the discussion about the housing problem in Brazil aiming the elaboration of projects to minimize such problems. The methodology used prioritized the integrated design conception through the elaboration of urbanistic diagnosis and project development at different levels. Thus, it is intended to contribute to the discussions regarding the academic formation of the student of architecture and urbanism, aware of the problems of society and its social role, as a transforming agent of urban space
\end{abstract}

Keywords: Social housing, built gaps, architecture projects.

\section{INTRODUÇÃO}

O presente artigo consiste na apresentação do processo de ensino, e resultados, desenvolvidos na disciplina de Projeto de Arquitetura, Urbanismo e Paisagismo $\mathrm{VI}$, com alunos do oitavo período do curso de Arquitetura e Urbanismo, do Centro Universitário Tiradentes (Unit), em Maceió, Alagoas.

MENEZES, C. A.; NOGUEIRA, F. H. S.; CAVALCANTI, A. S. M.; MACIEL, A. S. Edifício e Cidade: Reabilitação de vazios como estratégia de ensino de projeto. In: SIMPÓSIO BRASILEIRO DE QUALIDADE DO PROJETO NO AMBIENTE CONSTRUÍDO, 6., 2019, Uberlândia. Anais... Uberlândia: PPGAU/FAUeD/UFU, 2019. p. 1539-1549. DOI https://doi.org/10.14393/sbqp19138. 
Dentro do projeto pedagógico em vigência no curso, a referida disciplina se configura como a última oportunidade de trabalhar o projeto de arquitetura, urbanismo e paisagismo articuladas com problemáticas que estão presentes na maioria das cidades no nosso país.

Nesse sentido, é sabido que as cidades brasileiras, em geral, enfrentam hoje o desafio de lidar com os resultados catastróficos de um processo de urbanização acelerado, desordenado, desigual e perverso (MARICATO, 2010), que resultou em situações urbanas de extrema precariedade, nas quais grande parte da população está inserida, vivendo e usufruindo de uma baixíssima qualidade de vida.

O somatório de uma distribuição de renda extremamente injusta a um processo mercadológico da terra urbanizada excludente e a um histórico nacional de políticas públicas habitacionais ineficazes e/ou insuficientes, resultou em um cenário bastante contraditório, no qual uma grande quantidade de pessoas das classes mais pobres não têm acesso à habitação digna e em extensões urbanas qualificadas, sendo obrigadas a viver em âmbitos desordenadas, sem infraestrutura básica, em áreas de risco ou de preservação ambiental, sujeitas a alagamentos, deslizamentos e doenças e distante da maior oferta de trabalho; ou então são alocadas em conjuntos habitacionais estéreis, homogêneos e pobres em termos de qualidade arquitetônica, paisagística e construtiva (ROLNIK, 2008). Enquanto isso, impulsionadas pelos interesses econômicos, as centralidades (antigas e novas) da cidade recebem cada vez mais melhorias, sendo sempre diversificadas, valorizadas, e acessíveis apenas a uma pequena parcela da população (ROLNIK, 2017).

Este descompasso é agravado quando se observa a quantidade de pessoas sem moradia e o número de vazios urbanos existentes em diversas localidades da cidade, como ocorre no bairro do Centro de Maceió (SANTANA, 2006). O local passou por um profundo processo de transformação de uso, deixando de ser essencialmente misto, em seus primórdios, quando comerciantes, e outros moradores também habitavam o bairro, passando a ser quase que exclusivamente comercial.

A problemática dos vazios urbanos em áreas de infraestrutura consolidada tem sido frequentemente abordada por pesquisadores, que investigam as principais causas de sua existência, bem como suas especificidades. Os vazios urbanos não são constituídos apenas por terrenos desocupados, sem uso, mas também por estruturas construídas, que se encontram vazias ou subutilizadas. Segundo Santana (2006), no que se refere aos vazios construídos, as principais referências espaciais encontram-se nos centros históricos das cidades, cuja presença é justificada por conta das mudanças na dinâmica de sua ocupação.

Em um estudo realizado por Lins, et. al. (2010), constatou-se que o bairro do Centro de Maceió apresenta os melhores índices de urbanização (em relação à infraestrutura de abastecimento de água, esgotamento sanitário, pavimentação e concentração de atividades que geravam demanda por transporte urbano) é detentor também do menor indicador de densidade urbana.

Embora a legislação urbana, como o Estatuto da Cidade e o Plano Diretor Municipal, contenha instrumentos que, legalmente, são eficazes para 
combater a proliferação e consolidação de vazios urbanos, percebe-se que a sua efetiva utilização pela municipalidade ocorre ainda de uma forma muito incipiente, ou morosa, não contribuindo para o aproveitamento dessas áreas para a realização de sua função social. De modo inverso, no ano de 2017, a prefeitura de Maceió entregou o Residencial Maceió I, empreendimento habitacional do programa "Minha Casa Minha Vida", em uma região periférica da cidade que, embora esteja dentro da zona de expansão, contribui para o seu espraiamento. (CARDOSO, 2018).

Atualmente, em várias partes do Brasil, tem sido discutida (e aplicada) a inserção de habitação de interesse social em áreas centrais, como forma de dinamizar e diversificar os seus usos, além de proporcionar à população beneficiada moradia digna e com boa qualidade dos serviços públicos (WESZ, 2017).

Neste sentido, o trabalho desenvolvido na disciplina mencionada buscou, através da elaboração de projetos de arquitetura, urbanismo e paisagismo, discutir a temática da qualidade arquitetônica e construtiva da habitação de interesse social, da integração das propostas arquitetônicas ao contexto urbano do entorno, bem como do aproveitamento dos vazios urbanos centrais como moradia para a população de baixa renda, utilizando como estudo de caso o Edifício Palmares, localizado na região da Praça Doutor Manoel Valente de Lima, no bairro do Centro, em Maceió.

\section{METODOLOGIA}

Os procedimentos metodológicos priorizaram um ambiente onde a concepção projetual se desse de modo integrado, abrangendo aspectos da arquitetura, do urbanismo e do paisagismo em conjunto com as outras disciplinas do período. Esta abordagem associada não é exclusiva da disciplina em foco, mas sim uma postura que baliza todo o projeto pedagógico do curso de Arquitetura e Urbanismo do Centro Universitário Tiradentes (UNIT-AL). Vianna e Cavalcanti (2016) em artigo intitulado "Ensino do Urbanismo nos cursos de Arquitetura e Urbanismo: Tecendo a compreensão da cidade para a atividade projetual" pensam sobre como a reflexão e o desejo de uma formação discente mais conectada com a realidade das cidades do Brasil, guiou o desenvolvimento da abordagem pedagógica do curso.

Sendo assim, o curso definiu como foco principal o ato de projetar, no qual as questões arquitetônicas, urbanísticas e paisagísticas seriam tratadas conjuntamente. Todos os projetos elaborados durante a formação deverão contemplar as questões urbanas, aumentando a escala de acordo com a complexidade do tema, de acordo com o amadurecimento e o progresso do aluno (VIANNA; CAVALCANTI 2016, p.125).

Apesar desta integração nortear as disciplinas projetuais do curso, é necessário que a escolha da problemática que será abordada na disciplina viabilize esta intenção. Desse modo, a partir da repercussão do caso do desabamento do edifício Wilton Paes de Almeida, no Largo do Paissandú-SP no ano de 2018, despertou o interesse em trazer a discussão acerca da (re)ocupação de edifícios abandonados, o papel que desempenham atualmente e a reflexão sobre as centralidades urbanas. Mais especificamente foi proposta uma 
conjuntura onde a atividade projetual atravessasse esses temas, buscando associar teoria, reflexão e prática projetual.

Tendo essas questões como horizonte foi escolhida uma região do centro de Maceió que, além de se configurar como um dos núcleos iniciais de urbanização da cidade e hoje estar passando por um processo de mudanças, abriga alguns edifícios verticais abandonados. Dentro desse conjunto o edifício Palmares, escolhido como objeto de intervenção projetual, se destaca não só pela sua imponência (verticalidade acentuada em comparação com seu entorno) mas também pelo agressivo processo de deterioração de sua estrutura física. Em vista disso, o desafio lançado aos alunos foi de realizar uma proposta de um uso misto para o edifício Palmares (comércio/serviço e habitação de interesse social), e uma requalificação dos seus espaços adjacentes (Praça dos Palmares e trecho da Rua do Comércio).

Assim, foram elencadas uma série de etapas metodológicas que, gradativamente, foram trabalhadas dentro e fora de sala de aula subsidiando a proposta projetual. As atividades envolveram aulas expositivas dialogadas com o suporte de bibliografia específica acerca dos temas das centralidades urbanas, seus vazios (também os edificados) com o objetivo de capacitar os discentes acerca dos conceitos que gravitam em torno desta problemática.

Em complemento a teoria e com o objetivo de agregar ao vocabulário dos discentes sobre as diferentes possibilidades projetuais, foi proposta uma etapa de estudo de caso onde eles analisaram estratégias de reocupação (reforma, readequação, retrofit, reabilitação, dentre outros) em casos consolidados de reuso de edifícios (construídos ou não).

Após esta etapa os discentes iniciaram os primeiros contatos com o perímetro de estudo para realização de diagnóstico urbanístico e, após conclusão, o levantamento dos principais problemas e potencialidades da área. Além de fornecer embasamento para as ações projetuais, as visitas também servem para promover uma espécie de sensibilização dos alunos frente à realidade das cidades possibilitando uma ação projetual de certo modo mais complexa, para além da intervenção na tela do computador. Desse modo após a etapa de diagnóstico urbanístico, os discentes iniciaram as propostas projetuais.

\section{RESULTADOS E DISCUSSÕES}

\subsection{O objeto de estudo}

A cidade de Maceió foi consolidada como núcleo urbano propriamente dito apenas no século XIX, com o desenvolvimento do comércio, sendo elevada à categoria de vila em 1815, por alvará de D. João VI, quando foi desmembrada da antiga vila de Alagoas. Passou a ser sede da província, em 9 de dezembro de 1839 (ALTAVILA, 1988).

O porto foi a sua grande marca e que vai promover a ocupação mais efetiva da região. A proximidade do Porto de Jaraguá com o bairro do Centro, proporcionou a este um rápido desenvolvimento urbano, em função das relações comerciais que foram estabelecidas com as vilas situadas nas margens das lagoas Mundaú e Manguaba, que escoavam suas produções via Jaraguá, e não mais por meio do Porto dos Franceses, na antiga vila Santa 
Maria Madalena, atual cidade de Marechal Deodoro, conforme coloca Craveiro Costa (1981, p.17-18):

Ao findar o regime colonial, a povoação de Maceió já era um grande centro comercial de alguma importância, servindo de empório a uma vasta zona agrícola, que se desenvolvia pelo vale do Mundaú e do Paraíba, cortada por dois grandes caminhos aberto ao acaso da penetração sertaneja, com diversos centros açucareiros marginais. A produção, procurando saída mais fácil para o mar, fizera, naturalmente, o desenvolvimento comercial da povoação.

A vocação comercial do Centro logo se tornou evidente e ainda em fins do século XIX diversos estabelecimentos comerciais foram instalados onde, ainda hoje, são as principais ruas do bairro. Este desenvolvimento atraiu também diversos moradores para o local, fossem proprietários ou trabalhadores do comércio.

Em princípios do século XX, começaram a ser construídos edifícios que apresentavam grande valorização devido a sua localização: próximo ao mar, no centro urbano da cidade, o qual disponibiliza locais de convívio, sedes de diversos serviços públicos, ampla zona residencial e comercial, além do fácil acesso a outros locais da cidade.

Após a construção de referências arquitetônicas locais como o Hotel Bella Vista e o Edifício Breda, nos anos de 1960, foi erguido o Edifício Palmares, com catorze andares. O prédio que fora destinado inicialmente ao uso hoteleiro, a posteriori serviu como sede do Ministério da Saúde e outros órgãos federais, como a Anvisa (Agência Nacional de Vigilância Sanitária) e o IBGE (Instituto Brasileiro de Geografia e Estatística). De acordo com Rios (2017), em março de 2012, após seis laudos técnicos de condenação estrutural, por ordem da Justiça Federal, o edifício foi desocupado, passando por um processo de abandono e consequente deterioração e desmonte, que ocasionou a sua completa inutilização, restando hoje somente o esqueleto do antigo edifício (Figuras 1 e 2).

No que se refere ao seu entorno, nos dias atuais a área sofre com a falta de ordenamento público, déficits de infraestrutura como limpeza e iluminação, além da baixa diversificação de setores. Estas condições afetam de forma negativa à moradia, locomoção, produção e o lazer urbano, contribuindo para a perda da função social da construção. O abandono do edifício trouxe consigo algumas problemáticas, tais como o uso para atividades ilícitas, fator que pode contribuir com o aumento da violência local, e consequentemente, na diminuição do fluxo de pedestres na região. 


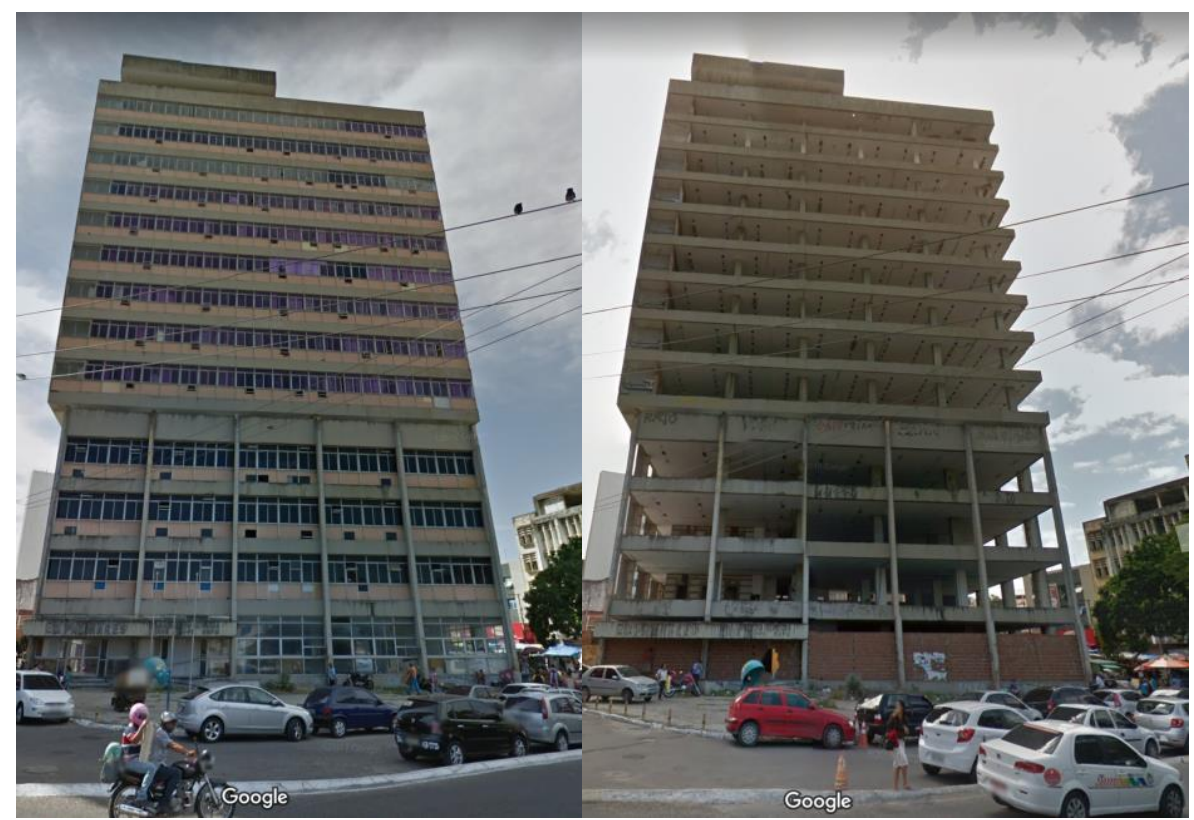

Figura 1 - Edifício Palmares em Abril de 2015 (Esquerda) e Agosto de 2016 (Direita) Fonte: Google Maps (2018) - Adaptado

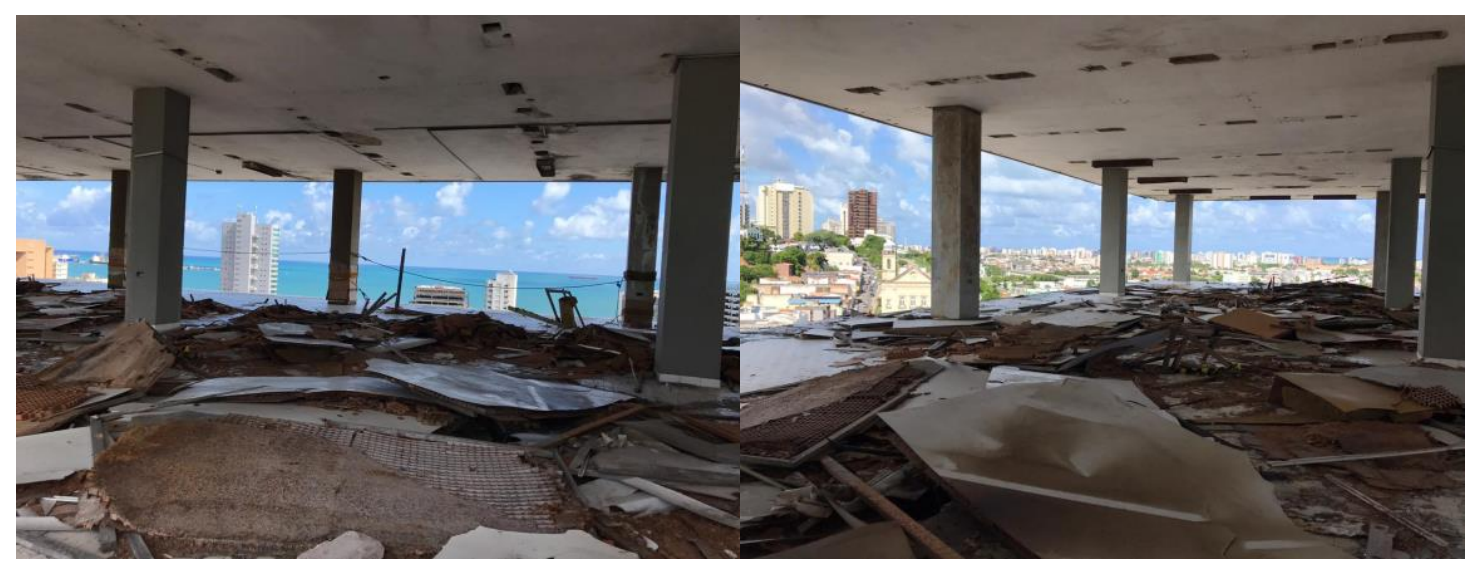

Figura 2 - Vista interior do Edifício Palmares a partir de um de seus pavimentos. Fonte: OTÁVIO (2019)

A área de intervenção selecionada na disciplina consiste em um perímetro urbano que compreende parte da Rua do Comércio, desordenadamente ocupada por comerciantes informais (Figura 3), a Praça Doutor Manoel Valente de Lima, conhecida como Praça dos Palmares, a qual possui diferentes usos e apropriações, com poucos atributos para permanência ou lazer e o Edifício Palmares. De forma geral, a área possui uso essencialmente diurno, visto que as edificações em seu perímetro são, em sua maioria, comerciais e de serviço, diminuindo seu uso no horário noturno. 

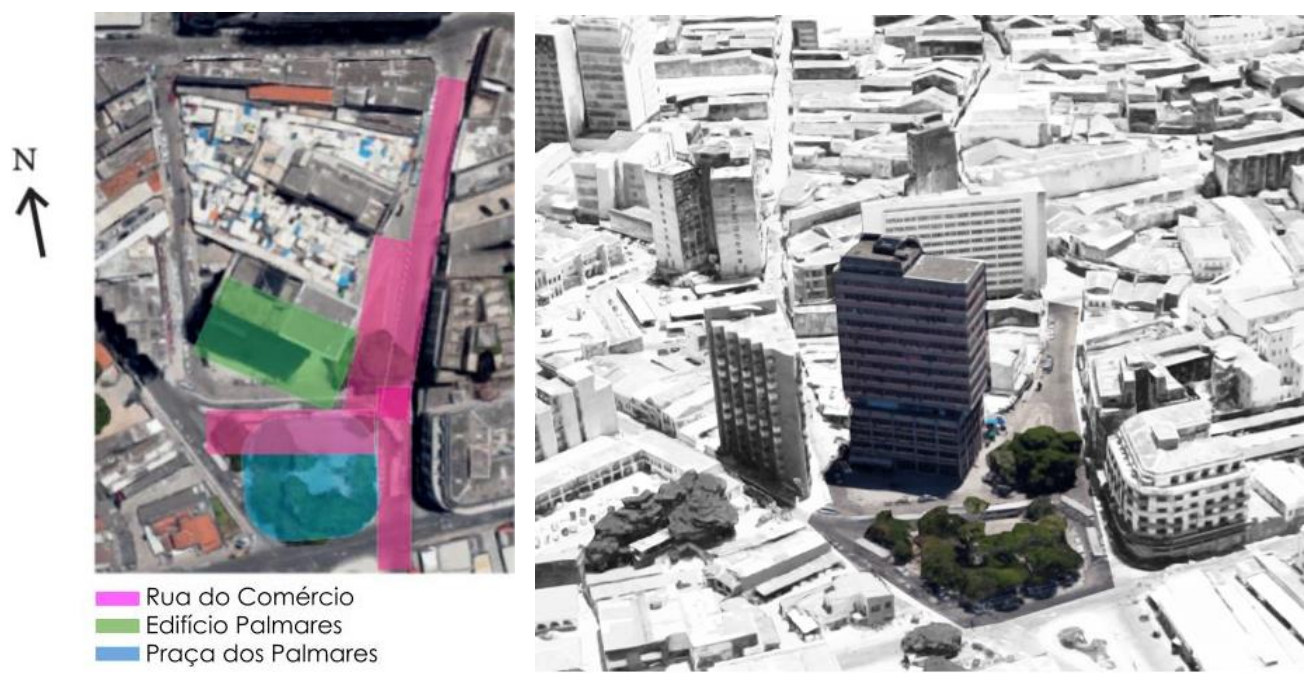

Figura 3 - Área de estudo

Fonte: Google Maps (2018) - Adaptado

\subsection{Desenvolvimento da proposta projetual}

Inicialmente, os grupos realizaram a etapa de levantamento de dados e pesquisa de campo, com leitura urbana, objetivando a construção de um arcabouço de informações, a partir da constatação dos principais problemas e potencialidades do edifício e da área de estudo, de modo embasar a elaboração das primeiras diretrizes de intervenção alinhadas com a realidade local.

O desenvolvimento da proposta de intervenção foi realizado em três etapas, abrangendo escalas diferentes de projeto. Os alunos elaboraram um estudo preliminar compreendendo o edifício, a Rua do Comércio e a praça. O principal objetivo foi desenvolver de forma integrada, uma proposta de projeto com uso misto no prédio, com habitação de interesse social, comércio e serviço; a requalificação da praça e a sua integração espacial e/ou visual com o edifício e o reordenamento da Rua do Comércio, considerando a permanência dos comerciantes informais.

Os principais desafios enfrentados pelos grupos foram as limitações espaciais de adequação de um edifício existente, com prioridade para a habitação e que conciliasse seus diferentes usos, favorecendo a privacidade e segurança dos moradores, bem como o ordenamento da Rua do Comércio, sem prejuízo para os comerciantes.

Na segunda etapa, os alunos desenvolveram o anteprojeto arquitetônico, na escala do edifício, pois a proposta na escala urbana foi aprimorada em paralelo na disciplina de Paisagismo. Os principais problemas nessa etapa consistiram em lidar com aspectos técnicos relacionados às instalações prediais, à estrutura e à circulação vertical e sua compatibilização com o projeto arquitetônico. Nesse sentido, os alunos foram impelidos a buscar soluções criativas para adequar o antigo edifício aos novos usos e às novas exigências técnicas e tecnológicas.

O projeto executivo foi realizado de forma reduzida, considerando o curto tempo da disciplina e a complexidade de variáveis existentes ao longo do trabalho. Nesse sentido, os grupos selecionaram um apartamento habitacional e desenvolveram, de forma pontual, projetos de paginação de piso, forro, 
iluminação, instalações elétricas e hidráulicas, detalhamentos de esquadrias e áreas molhadas. Esta última etapa serviu para convocar a discussão com os alunos acerca da importância do detalhamento executivo dentro do processo de projeto.

Em comum, as propostas buscaram responder projetualmente acerca da integração da área com o seu entorno, o uso misto viabilizou a implementação do recurso de fachadas ativas e a priorização do pedestre e do uso coletivo do espaço público, com áreas de permanência equipadas e vegetadas (Figuras 4, 5, 6 e 7).

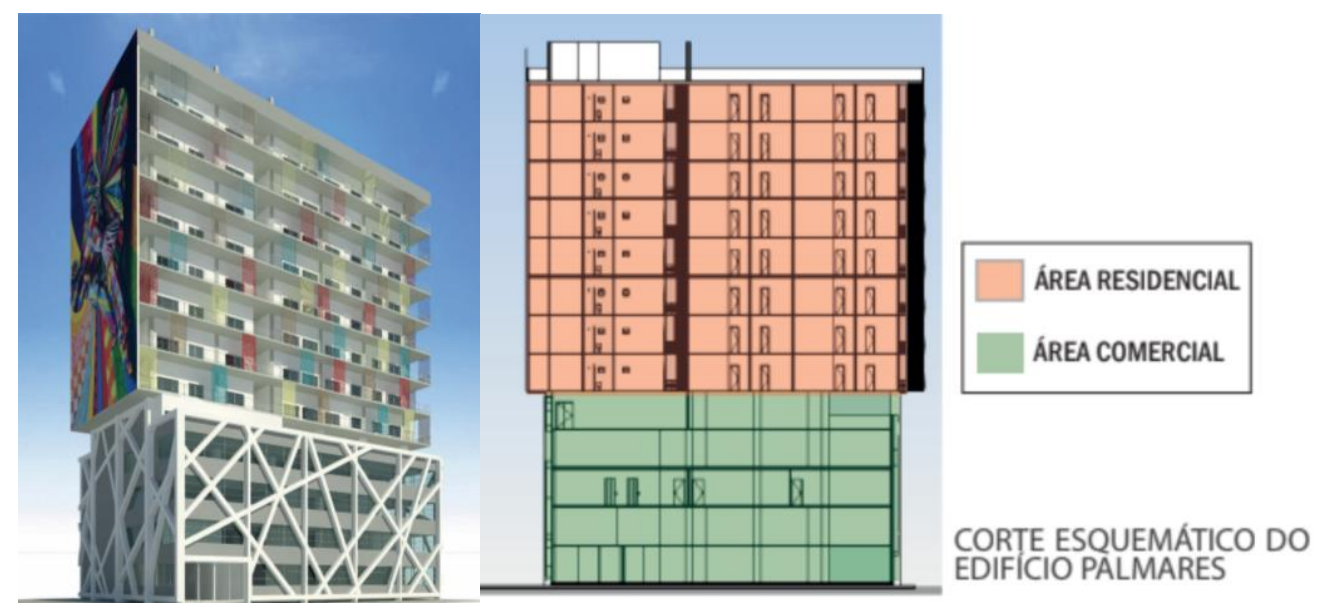

Figura 4 - Exemplo de proposta projetual desenvolvida por uma das equipes Fonte: MONTEIRO; AZEVEDO; SANTOS, 2018

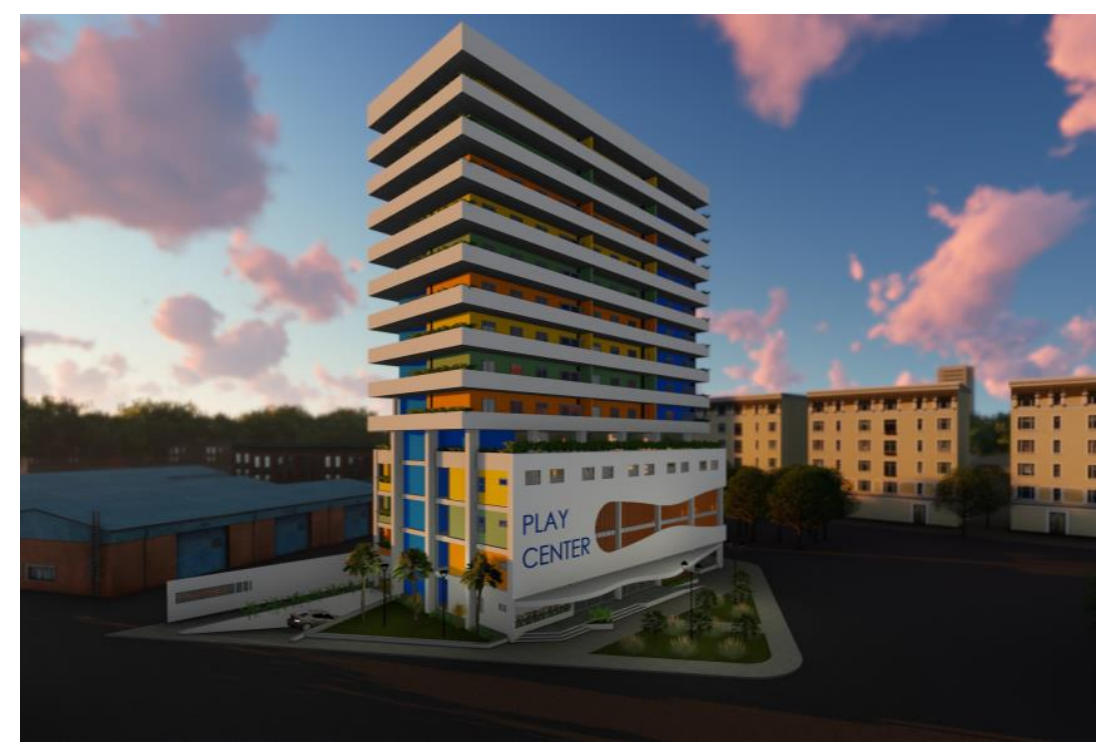

Figura 5 - Exemplo de proposta projetual desenvolvida por uma das equipes Fonte: BARBOSA; COSTA, 2019 

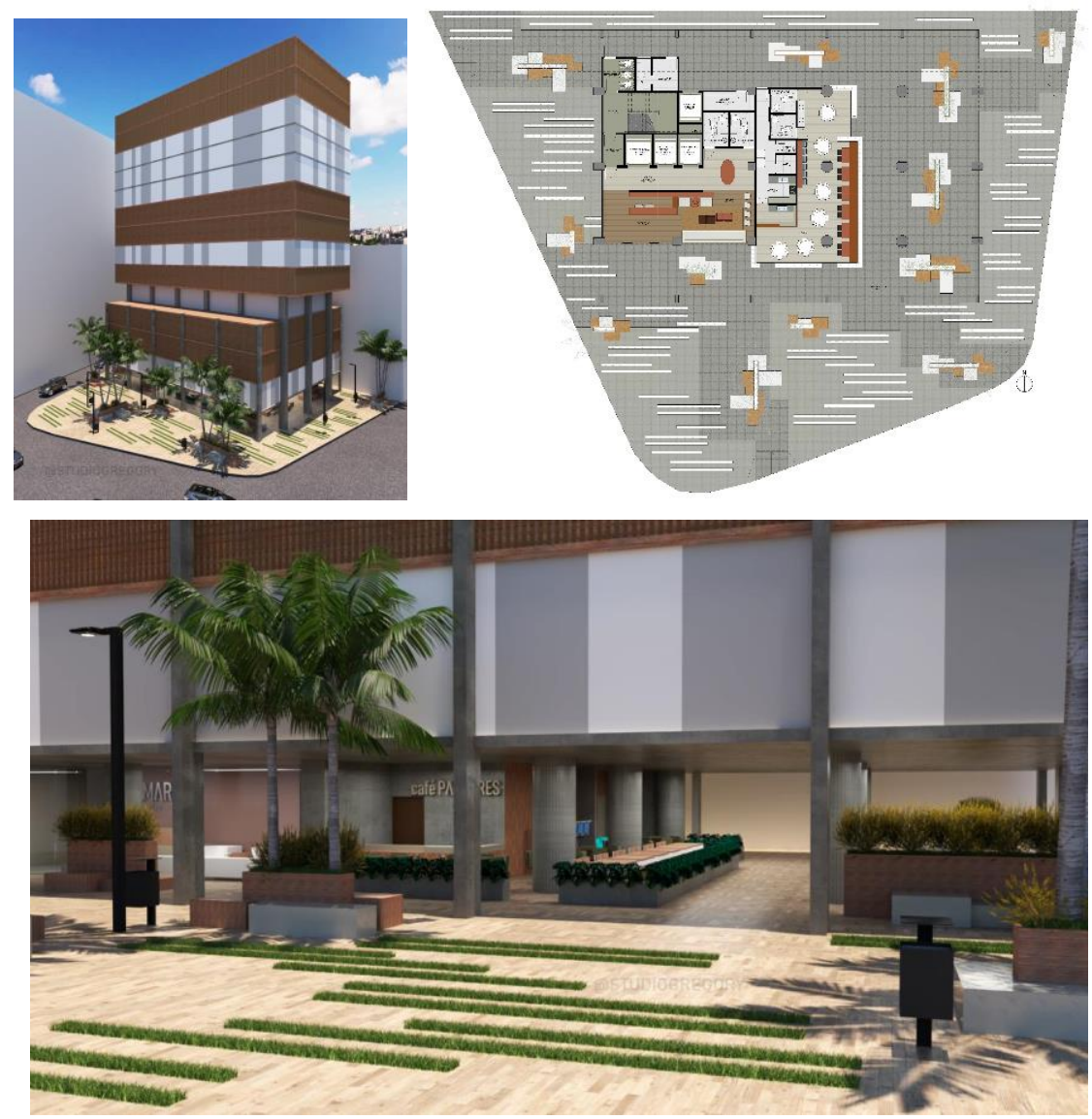

Figura 6 - Exemplo de proposta projetual desenvolvida por uma das equipes Fonte: SILVA; EVERALDO NETO, 2019

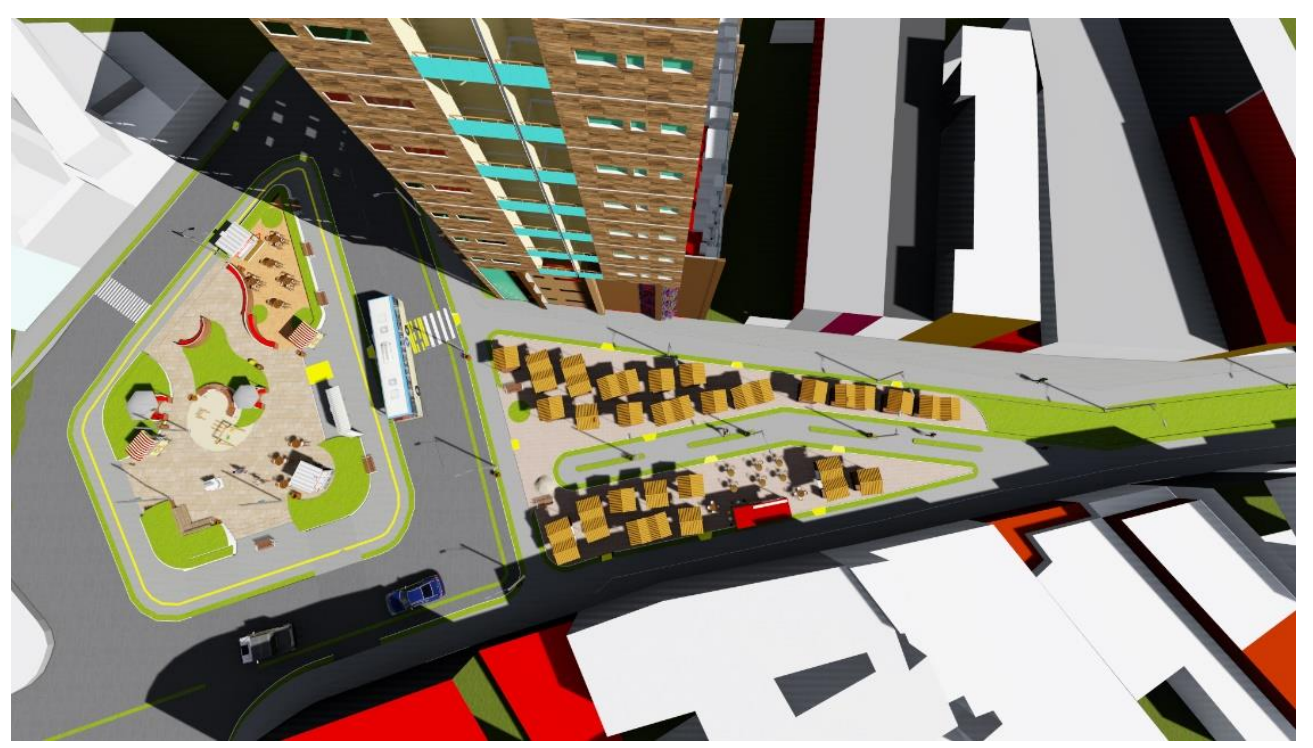

Figura 7 - Exemplo de proposta projetual desenvolvida por uma das equipes Fonte: CAVALCANTI; MACIEL, 2018 
No decorrer do desenvolvimento das atividades projetuais, notou-se que as principais dificuldades enfrentadas pelos discentes envolveram a falta de dados históricos suficientes sobre a formação local, expondo de forma simplista a divulgação de características que condensam o entendimento, preservação e identidade do espaço, visto que a área possui grande influência diante da economia, cultura e patrimônio maceioense. $E$, portanto, tornando-se fator principal que desencadeou os demais obstáculos, principalmente, acerca dos fluxos, sejam eles de pedestres, automóveis e até sua ausência, em determinados horários.

Entre os aspectos correspondentes às questões sociais, estruturais e de uso, diante da elaboração do projeto de intervenção, os principais desafios enfrentados pelos alunos foram: I) buscar soluções para as questões acerca da segurança local; II) dificuldade na coleta de dados, devido à falta de manutenção e fluxos assíduos; III) compatibilização dos projetos da edificação e entorno; IV) compatibilização do sistema estrutural existente com as novas demandas de uso - sobretudo o uso residencial, que preconizava maior subdivisão do espaço da laje, a fim de compor os apartamentos, os quais possuíam como prerrogativa várias tipologias; $V$ ) adequação do projeto às demandas atuais no que se refere o combate a incêndio, adaptando a circulação vertical já existente; VI) escolha adequada de vedação

\section{CONSIDERAÇÕES FINAIS}

O processo na disciplina buscou privilegiar uma inserção dos discentes em uma prática projetual contextualizada com os acontecimentos da cidade "real", se afastando do exercício isolado seja no campo da arquitetura, do urbanismo ou do paisagismo, mas buscando a integração destes em um processo mais complexo.

A reflexão acerca do desenvolvimento das cidades, surgimento de novas centralidades e consequente "abandono" das regiões centrais tradicionais, articuladas com a problemática da demanda habitacional, contribui com a formação dos discentes ao demandar habilidades distintas de atuação do arquiteto e urbanista.

No âmbito pedagógico, o exercício proposto estimulou a coordenação horizontal com a disciplina de paisagismo, como também verticalmente ao resgatar conteúdos de todo o curso. Além disso, o formato de desenvolvimento das propostas, em grupo, permitiu que fossem trabalhados aspectos da formação dos alunos para além das questões técnicas como, por exemplo, o trabalho colaborativo.

\section{AGRADECIMENTOS}

Agradecemos a todos os discentes que participaram da disciplina de Projeto de Arquitetura, Urbanismo e Paisagismo VI do Centro Universitário Tiradentes (UNIT-AL) durante o período de 2018.2 e 2019.1, em especial ao que gentilmente nos cederam as imagens de seus trabalhos. 


\section{REFERÊNCIAS}

ALTAVILA, Jayme de. História da Civilização das Alagoas. Maceió: Edufal, 1988.

CARDOSO, Andressa Basílio Britto. Habitação de interesse social: um olhar sobre o residencial Maceió I. TCC (graduação em Arquitetura e Urbanismo) Centro Universitário Tiradentes, Maceió, 2018.

COSTA, Craveiro. Maceió. 2. ed. Maceió: SERGASA, 1981.

LINS, R. D. B. et al. Vazios urbanos: entendendo as especificidades territoriais e ambientais das terras sem ocupação do litoral norte da cidade de Maceió, Alagoas, Brasil. Pluris, 2010, $4^{\circ}$ Congresso para o Planeamento Urbano, Regional, Integrado e Sustentável. Disponível em:

http://pluris2010.civil.uminho.pt/Actas/PDF/Paper610.pdf. Acessado em 08/06/2019.

RIOS, Odilon. Prédio do INSS vira 'esqueleto' sem dono em Maceió. Disponível em: https://reporternordeste.com.br/predio-do-inss-vira-esqueleto-sem-donoem-maceio/. Acesso em: 10 de Junho de 2019.

ROLNIK, R.; SANTORO, P. F. Novas frentes de expansão do complexo imobiliário-financeiro em São Paulo. Cadernos Metrópole. São Paulo, v. 19, n. 39, pp. 407-431, maio/ago 2017.

ROLNIK, R. Acesso ao solo urbano: limites e possibilidades. PINHEIRO, Otilie Macedo... [ET AL.]. Acesso à terra urbanizada: implementação de planos diretores e regularização fundiária plena. Florianópolis: UFSC; Brasília: Ministério das Cidades, 2008.

SANTANA, Lucycleide Santos. Os vazios urbanos nos centros de cidades como lugar para a habitação de interesse social : o caso de Maceió / AL. 2006. 169 f. Dissertação (Mestrado em Dinâmicas do Espaço Habitado) - UFAL, Maceió, 2006.

VIANNA, M. P.; CAVALCANTI, D. B. Ensino do urbanismo nos cursos de Arquitetura e Urbanismo: tecendo a compreensão da cidade para a atividade projetual. Gestão e Tecnologia de Projetos, São Carlos, v. 1 1, n. 1, p. 121-133, jan./jun. 2016. Disponível em:

http://dx.doi.org/10.1 1606/gtp.v1 1i1.99209. Acessado em 20/05/2019.

VILLAÇA, F. A recente urbanização brasileira. In: CASTRIOTA, Leonardo Barci (Org.) Urbanização brasileira: redescobertas. Belo Horizonte: C/ Arte, 2003.

WESZ, J. G. B., Reabilitação de Áreas Centrais com Habitação de Interesse Social: Benefícios para a Cidade e para seus Usuários. Anais do XVII Encontro Nacional da Associação Nacional de Pós-Graduação e Pesquisa em Planejamento Urbano e Regional. São Paulo, 2017. 